\title{
Change over time in ability to perform activities of daily living in myotonic dystrophy type 1
}

\author{
Erik Landfeldt ${ }^{1}$ (D) Nikoletta Nikolenko ${ }^{2} \cdot$ Cecilia Jimenez-Moreno $^{3,4} \cdot$ Sarah Cumming $^{5} \cdot$ Darren G. Monckton $^{5}$. \\ Catharina G. Faber ${ }^{6} \cdot$ Ingemar S. J. Merkies $^{6,7} \cdot$ Grainne Gorman $^{8} \cdot$ Chris Turner $^{2,9} \cdot$ Hanns Lochmüller ${ }^{10,11}$
}

Received: 17 February 2020 / Revised: 25 May 2020 / Accepted: 1 June 2020 / Published online: 15 June 2020

(c) The Author(s) 2020

\begin{abstract}
Objective The objective of this longitudinal, observational study was to investigate change over time in ability to perform activities of daily living in myotonic dystrophy type 1 (DM1).

Methods Adults with genetically confirmed DM1 were recruited as part of the PhenoDM1 study in the UK. Data on activities of daily living were recorded through the DM1-Activ ${ }^{C}$ at baseline and a follow-up visit after $12( \pm 3)$ months. A subset of patients had advanced genetic testing to determine the size of the progenitor allele.

Results Our sample comprised 150 patients with DM1 (mean age: 45 years; 52\% female). Mean follow-up was 383 days. Mean DM1-Activ ${ }^{\mathrm{C}}$ total score at baseline was 71.24 (95\% confidence interval 67.77-74.71) and at the follow-up visit 69.04 (65.54-72.54). Approximately $43 \%$ of patients had a lower score at the follow-up visit (indicating a decreased ability to perform activities of daily living), 24\% a higher score (indicating an increased ability), and 33\% the same score at baseline and follow-up. The mean annual change in the DM1-Activ ${ }^{\mathrm{C}}$ total score, estimated at $-2.06(-3.54$ to -0.59$)$, was significantly related to patients' baseline score, but not sex, disease duration, timed test results, or cytosine-thymine-guanine repeat length. Conclusions Change over time in ability to perform activities of daily living as recorded through the DM1-Activ ${ }^{\mathrm{C}}$ varies substantially between patients with DM1. Our data contribute to the understanding of the natural evolution of the disease, and should be helpful to inform the design of future trials based on the DM1-Activ ${ }^{\mathrm{C}}$.
\end{abstract}

Keywords Disability · Participation · Activities of daily living · PhenoDM1

\section{Introduction}

Myotonic dystrophy type 1 (DM1) is a progressive, yet highly heterogeneous multi-system disorder affecting muscle strength and mobility, amongst many other clinical domains [1]. Individually or collectively, these disease manifestations lead to impaired performance in daily life and restriction in social participation $[2,3]$. The clinical variability of DM1, which partly has been attributed to the nature of the underlying gene defect as expressed via unstable triplet repeats of

Erik Landfeldt and Nikoletta Nikolenko equal contribution.

Electronic supplementary material The online version of this article (https://doi.org/10.1007/s00415-020-09970-6) contains supplementary material, which is available to authorized users.

Erik Landfeldt

erik.landfeldt@ki.se

Extended author information available on the last page of the article the $D M P K$ gene, makes the design of clinical trials in this indication challenging, particularly the identification and selection of outcome measures that are relevant and fit for purpose to measure drug benefits across the full spectrum of disease severity and morbidity $[4,5]$.

The DM1 activity and participation scale for clinical use $\left(\right.$ DM1-Activ $\left.{ }^{\mathrm{C}}\right)$ is an outcome tool developed to measure ability to perform activities of daily living (e.g., taking a shower, visiting family or friends, and walking up a flight of stairs) in patients with DM1 [6, 7]. It was designated as the primary endpoint in a recently completed clinical trial of cognitive behavioral therapy with optional graded exercise therapy in patients with DM1 (i.e., the OPTIMISTIC trial) [8]. However, to date, no study has in detail examined changes over time in outcomes from the DM1-Activ ${ }^{\mathrm{C}}$ aside changes in total scale scores in patients with DM1. Accordingly, the objective of this study was to investigate natural changes over time in ability to perform activities of daily living as recorded using the DM1-Activ ${ }^{\mathrm{C}}$ in patients with DM1 in 
the UK receiving no specific treatment. A specific aim was to examine the association between perceived performance at baseline, sex, disease duration, and cytosine-thymineguanine (CTG) repeat length, and change across follow-up, respectively.

\section{Methods}

\section{Study design and patient sample}

This was a longitudinal, observational study of patients with genetically confirmed DM1 recruited from Newcastle University (Newcastle upon Tyne, UK) and University College London Hospitals NHS Foundation Trust (London, UK) as part of the Myotonic Dystrophy Type 1 Deep Phenotyping to Improve Delivery of Personalized Medicine and Assist in the Planning, Design and Recruitment of Clinical Trials (PhenoDM1) study (ClinicalTrials.gov identifier: NCT02831504). The following inclusion criteria were imposed for patient study eligibility: (1) $\geq 18$ years of age, (2) genetically confirmed diagnosis of DM1, and (3) ability to perform the $10 \mathrm{~m}$ walking test at selected pace without any assistance (walking devices allowed). All participants provided informed consent to participate in the study and ethical approval was granted by the Newcastle and North Tyneside Ethics Committee (reference: NE/15/0178).

\section{Study procedures and outcomes}

Eligible patients were asked to complete the DM1-Activ ${ }^{\mathrm{C}}$ as part of the study visits. The DM1-Activ ${ }^{\mathrm{C}}$ was initially developed in 2010 [6], but re-constructed in 2015 [7], and the current version encompasses a total of 25 items, each described in three levels. The tool has been developed using modern psychometric analysis (i.e., Rasch analysis [9]) and has been shown to adhere to the epistemological requirements for stable measures, including linearity, invariance, and unidimensionality [10, 11]. At baseline, we also recorded basic demographic and clinical characteristics (as listed in Table 1). The 6-minute walk test (6MWT) was performed at baseline and follow-up in a 25-m long corridor in Newcastle and 20-m long corridor in London. Per currently agreed procedures [4], patients received feedback every minute of the current test time (i.e., the time left of the total 6-m test time).

\section{Genetic analysis}

Recent research [12] has shown that the length of the repeat expansion at birth as expressed by the progenitor allele is the most relevant predictor of disease onset and severity later in life, while disease progression is closely related to the rate of somatic expansion over time within different tissues (approximated as the difference between modal length at the time of DNA sampling and the progenitor allele, where the modal allele length is the most common repeat length in that tissue at time of sampling). For our analysis, to allow comparison of data, we included both CTG repeat counts from blood DNA (i.e., the estimated progenitor and modal allele length). CTG repeat length was estimated from blood DNA by the small-pool PCR assay as described by Gomes-Pereira et al. [13] using the CTG repeat-flanking primers DM-C and DM-DR [12, 14]. Replicate reactions were separated by gel electrophoresis, Southern blotted and hybridised using a ${ }^{32} \mathrm{P}$-labelled $56 \times \mathrm{CTG}$ repeat probe. Bands were detected by autoradiography and sized by comparison against the DNA molecular weight marker, using CLIQS software (TotalLab UK Ltd.). The bottom edge of the expanded allele bands was used to determine the estimated progenitor allele length [12]. The densest part of the expanded allele bands was used to estimate the modal allele length at the time of DNA sampling (i.e., CTG modal alleles). The CTG repeat length analysis was only available for patients recruited via Newcastle University, Newcastle upon Tyne.

\section{Statistical analysis}

We calculated the distribution of replies across all items and levels within the DM1-Activ ${ }^{\mathrm{C}}$ and the corresponding mean item scores, ranging from 0 ("Not possible to perform") to 2 ("Possible, without any difficulty"), as well as the mean transformed total instrument score (ranging between 0 and 100, where a higher/lower score indicates a higher/lower ability to perform activities of daily living) at baseline and the follow-up visit. We related the total score to two previously derived [7] threshold values (amended for the transformed scale): $\leq 30$ (indicating severe limitations in activities of daily living), and $>70$ (indicating relatively few limitations). We calculated the unadjusted mean change in DM1-Activ ${ }^{\mathrm{C}}$ total scores from baseline to follow-up for the total sample, as well as for patients with a higher and lower score at the follow-up visit, respectively. To account for differences in follow-up length, we also derived unadjusted mean annual changes in DM1-Activ ${ }^{\mathrm{C}}$ total scores (assuming a linear change over time in DM1-Activ ${ }^{\mathrm{C}}$ total scores at the patient level). We compared changes in DM1Activ $^{\mathrm{C}}$ total scores by sex and type of DM1 defined based on age at onset of disease [congenital: $\leq 11$ months; classical: 12 months -40 years; and late adult: $>40$ years, with a Muscular Impairment Rating Scale (MIRS) score < III, and $<150$ CTG repeats] using Welch's $t$ test. We also compared demographic and clinical characteristics of patients with a lower DM1-Activ ${ }^{\mathrm{C}}$ total score at the follow-up (indicating a decreased ability to perform activities of daily living), a higher score (indicating an increased ability), and the same score using Welch's analysis of variance (ANOVA) 
Table 1 Baseline demographic and clinical characteristics of the patient sample

\begin{tabular}{|c|c|c|c|c|c|}
\hline & Total sample $(n=150)$ & $\begin{array}{l}\text { Lower total score } \\
\text { (i.e., worsened ability) } \\
\text { at follow-up }(n=65)\end{array}$ & $\begin{array}{l}\text { Same total } \\
\text { score at follow- } \\
\text { up }(n=49)\end{array}$ & $\begin{array}{l}\text { Higher total score } \\
\text { (i.e., improved ability) } \\
\text { at follow-up }(n=36)\end{array}$ & $p$ value $\dagger$ \\
\hline Age, mean (SD) years & $45(14)$ & $50(12)$ & $39(16)$ & $46(11)$ & 0.001 \\
\hline Sex, female & $78(52 \%)$ & $38(58 \%)$ & $24(49 \%)$ & $16(44 \%)$ & 0.352 \\
\hline Age at first symptoms, mean (SD) years ${ }^{a}$ & $26(17)$ & $28(18)$ & $23(17)$ & $27(16)$ & 0.343 \\
\hline Disease duration, mean (SD) year ${ }^{b}$ & $20(12)$ & $22(13)$ & $16(12)$ & $20(11)$ & 0.090 \\
\hline \multicolumn{6}{|l|}{ Type of DM1 ${ }^{\mathrm{c}}$} \\
\hline Congenital & $8(5 \%)$ & $2(3 \%)$ & $5(11 \%)$ & $1(3 \%)$ & 0.141 \\
\hline Classical & $101(70 \%)$ & $45(70 \%)$ & $29(64 \%)$ & $27(75 \%)$ & 0.583 \\
\hline Late onset & $36(25 \%)$ & $17(27 \%)$ & $11(24 \%)$ & $8(22 \%)$ & 0.888 \\
\hline Part-time wheelchair dependency & $22(15 \%)$ & $10(15 \%)$ & $4(8 \%)$ & $8(22 \%)$ & 0.190 \\
\hline \multicolumn{6}{|l|}{ 6-minute walk test } \\
\hline Baseline result, mean (SD) meters ${ }^{\mathrm{d}}$ & $422(152)$ & 407 (129) & $489(155)$ & 375 (137) & 0.002 \\
\hline Follow-up result, mean (SD) meters ${ }^{\mathrm{e}}$ & $404(157)$ & $356(149)$ & $491(151)$ & $368(132)$ & $<0.001$ \\
\hline 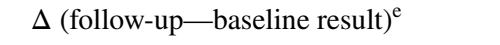 & $-30(71)$ & $-52(82)$ & $-14(57)$ & $-14(56)$ & 0.015 \\
\hline \multicolumn{6}{|c|}{ Muscular impairment rating scale (MIRS) score } \\
\hline I & $19(13 \%)$ & $7(11 \%)$ & $9(18 \%)$ & $3(8 \%)$ & 0.323 \\
\hline II & $40(27 \%)$ & $15(23 \%)$ & $20(41 \%)$ & $5(14 \%)$ & 0.015 \\
\hline III & $30(20 \%)$ & $15(23 \%)$ & $8(16 \%)$ & $7(19 \%)$ & 0.669 \\
\hline IV & $47(31 \%)$ & $22(34 \%)$ & $9(18 \%)$ & $16(44 \%)$ & 0.032 \\
\hline $\mathrm{V}$ & $14(9 \%)$ & $6(9 \%)$ & $3(6 \%)$ & $5(14 \%)$ & 0.477 \\
\hline Education, mean (SD) years completed ${ }^{\mathrm{d}}$ & $15(3)$ & $15(3)$ & $16(3)$ & $15(3)$ & 0.076 \\
\hline \multicolumn{6}{|l|}{ Current occupation } \\
\hline Employed & $61(41 \%)$ & $22(34 \%)$ & $26(53 \%)$ & $13(36 \%)$ & 0.096 \\
\hline Retired & $22(15 \%)$ & $10(15 \%)$ & $7(14 \%)$ & $5(14 \%)$ & 0.975 \\
\hline Long-term sick leave & $35(23 \%)$ & $17(26 \%)$ & $5(10 \%)$ & $13(36 \%)$ & 0.016 \\
\hline Unemployed/other & $32(21 \%)$ & $16(25 \%)$ & $11(22 \%)$ & $5(14 \%)$ & 0.440 \\
\hline Follow-up, mean (SD) days & $383(47)$ & $382(40)$ & $393(50)$ & $373(54)$ & 0.202 \\
\hline
\end{tabular}

Data presented as $n(\%)$, if not specified otherwise. Total sample size: ${ }^{\mathrm{a}} n=144 ;{ }^{\mathrm{b}} n=143 ;{ }^{\mathrm{c}} n=145 ;{ }^{\mathrm{d}} n=140$; and ${ }^{\mathrm{e}} n=136$. Because of rounding, percentages might not add up to $100 \%$ exactly

DM1 myotonic dystrophy type 1

†Comparing patients with a higher DM1-Activ ${ }^{\mathrm{C}}$ total score, same score, and lower score at follow-up

models and Pearson's Chi-square test. We estimated Pearson's correlation coefficients to investigate the crude relationship between disease duration (measured from onset), CTG repeat length, MIRS score, and 6MWT result, respectively, and annual changes in DM1-Activ ${ }^{\mathrm{C}}$ total scores. In addition, to further investigate the association between the baseline DM1-Activ ${ }^{\mathrm{C}}$ total score (which may serve as a meaningful and easily measurable criterion for future clinical trials) and annual changes in total scores, we fitted an ordinary least squares linear regression model to our study data, with annual change in the DM1-Activ ${ }^{\mathrm{C}}$ total score as the dependent variable and the baseline score as the primary explanatory variable. To adjust for confounding effects, the model was specified to also include sex, age, and estimated progenitor CTG repeat length, as well as an interaction variable between estimated progenitor CTG repeat length (normalised by log transformation) and age, per previous research [12]. Robust standard errors were derived using the Huber/White/sandwich estimator. All analyses were conducted in Stata 14 (StataCorp, College Station, TX, USA).

\section{Results}

A total of $n=213$ patients with DM1 met all study inclusion criteria and were enrolled into the PhenoDM1 study. Of these, $n=150$ completed the DM1-Activ ${ }^{\mathrm{C}}$ in accordance with instructions at both the baseline and follow-up visit. Demographic and clinical characteristics of the sample are presented in Table 1. At baseline, less than half (41\%, 61 of 150) of all patients reported being employed (parttime or full-time) and one-third $(33 \%, 43$ of 132) of those 
of working age (i.e., $<65$ years) were retired or on longterm sick leave. Mean estimated progenitor and modal allele length, based on data for 56\% (84 of 150) and 55\% (82 of 150 ) of patients, respectively, were 234 CTG repeats (SD: 171, range: 55-916) and 465 CTG repeats (344, 62-1441). In the subset of patients from the PhenoDM1 study analyzed as part of this work, three had variant repeat interruptions.

At baseline, the mean DM1-Activ ${ }^{\mathrm{C}}$ total score in our sample was estimated at 71.24 [SD: 21.53 , range: $28-100$, $95 \%$ confidence interval (CI) 67.77-74.71]. Approximately $1 \%$ ( 2 of 150 ) scored $\leq 30$ (indicating severe limitations in activities of daily living), and $48 \%$ (72 of 150) scored $>70$ (indicating relatively few limitations). At follow-up, after a mean duration of 383 days, the mean DM1-Activ ${ }^{\mathrm{C}}$ total score in our sample was estimated at 69.04 (SD: 21.67, range: $25-100,95 \%$ CI $65.54-72.54)$, with the same proportions scoring $\leq 30$ and $>70$.

The unadjusted mean change in the DM1-Activ ${ }^{\mathrm{C}}$ total score during follow-up was estimated at -2.20 (SD: 9.50, range: -47 to $28,95 \% \mathrm{CI}-3.73$ to -0.67 ). Approximately $43 \%$ (65 of 150) of patients had a lower score at the followup visit (indicating a decreased ability to perform activities of daily living), $24 \%$ (36 of 150) a higher score (indicating an increased ability), and 33\% (49 of 150) the same score at baseline and follow-up. The mean unadjusted change in patients with a lower total score at follow-up was -9.68 (SD: 7.74 , range: -47 to $-1,95 \%$ CI -11.60 to -7.76 ), and a higher total score 8.31 (SD: 7.13 , range: $1-28,95 \% \mathrm{CI}$ 5.89-10.72). Demographic and clinical characteristics of the three patient groups are presented in Table 1.

Accounting for the patient-specific length of follow-up, and assuming a linear change (at the patient level) in DM1Activ $^{\mathrm{C}}$ total scores, the unadjusted mean annual change in the DM1-Activ ${ }^{\mathrm{C}}$ total score in the total sample population was -2.06 (SD: 9.14 , range: -43.57 to $34.55,95 \%$ CI -3.54 to -0.59 ) (Fig. 1). The corresponding estimate for patients with a lower total score at follow-up was -9.25 (SD: 7.26, range: -43.57 to $-0.98,95 \% \mathrm{CI}-11.05$ to -7.45 ), and a higher score 8.10 (SD: 7.14, range: 0.90-34.55, 95\% CI 5.68-10.51). We found no significant differences between women and men in the unadjusted mean annual change in the DM1-Activ ${ }^{\mathrm{C}}$ total score across follow-up (-2.24 vs. -1.87 , $p=0.808)$. The unadjusted mean annual change in the DM1Activ $^{\mathrm{C}}$ total score was -1.96 (SD: 9.25 , range: -43.57 to $24.64,95 \%$ CI -3.79 to -0.13 ) for patients with classical DM1, -1.48 (SD: 7.32 , range: -17.18 to $9.13,95 \%$ CI - 7.61 to 4.64) for congenital DM1, and - 2.69 (SD: 9.95, range: $-20.93-34.55,95 \% \mathrm{CI}-6.06$ to 0.68 ) for late onset DM1 (classical vs. congenital: $p=0.887$; classical vs. late onset: $p=0.690$; and congenital vs. late onset: $p=0.748)$. In patients with variant repeat interruptions $(n=3)$, the mean annual change in the DM1-Activ ${ }^{\mathrm{C}}$ total score was -2.63 (SD: 7.54, range: - 5.09-9.99, 95\% CI - 16.12-21.37).

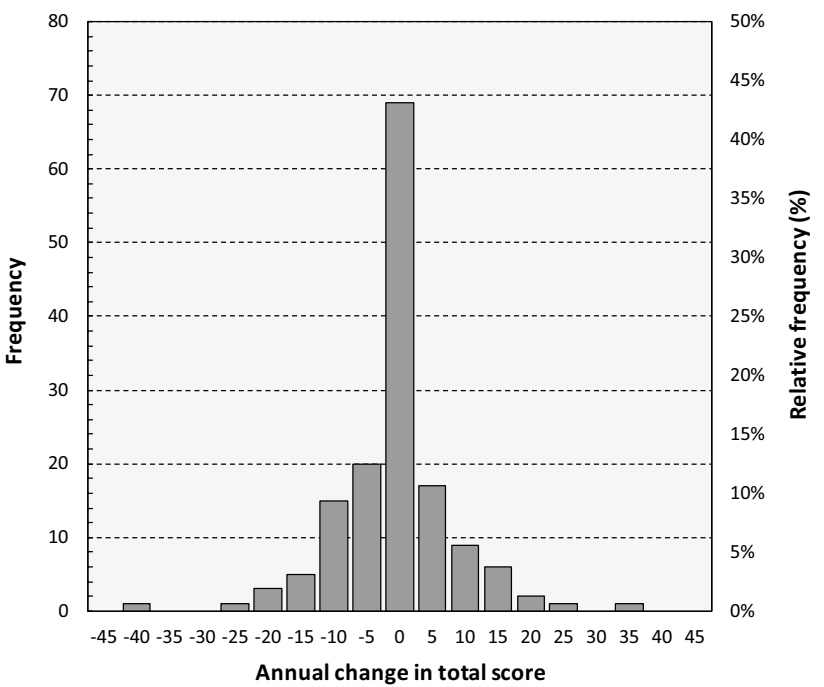

Fig. 1 Histogram of annual changes in DM1-Activ ${ }^{\mathrm{C}}$ total scores. A higher/lower score indicates a higher/lower ability to perform activities of daily living

Changes in scores were not significantly different across categories of current occupation (all $p>0.479$ ).

Table 2 summarizes changes during follow-up to the individual items within the DM1-Activ ${ }^{\mathrm{C}}$ for the total sample, as well as patients with a higher total score (i.e., an improved ability to perform activities of daily living) and lower total score (i.e., a worsened ability) at follow-up, respectively. For example, $86 \%$ (31 of 36) of patients who had a higher total score at the end of the follow-up provided the same answer at the baseline and follow-up visit to the question pertaining to their ability to eat soup. As shown in the table, replies to most items did not change from the baseline to the follow-up visit. For the subgroup with a higher total score at follow-up, the item with the largest positive change (i.e., an increased score from 0 to 1 , or 1 to 2) was "Carry and put down heavy object (10 kg)", where 44\% (16 of 36) of patients indicated improvement in their ability, followed by "Serve coffee/tea on a tray" $(42 \%, 15$ of 36), and "Stand on one leg" (36\%, 13 of 36). Worsened ability (i.e., a decreased item score from 2 to 1 , or 1 to 0 ) for this subgroup of patients was first and foremost noted for "Stand up from squatting position" (17\%, 6 of 36), and "Dress your lower body" and "Wash your upper body" (14\%, 5 of 36, respectively). For patients with a lower total score at follow-up, the largest improvement was noted for "Stand up from squatting position", where 11\% (7 of 65) had a higher item score, followed by "Walk three flights of stairs" and "Carry and put down heavy object $(10 \mathrm{~kg})$ " ( $8 \%, 5$ of 65 , respectively). The largest loss in ability for this subgroup concerned "Stand up from squatting position", where $38 \%$ ( 25 of 65 ) of patients had a lower item score at follow-up, followed by "Dance" (34\%, 22 of 65). In the total sample, the item exhibiting the largest positive change 
Table 2 Changes from baseline to follow-up to individual items within the DM1-Activ ${ }^{\mathrm{C}}$

\begin{tabular}{|c|c|c|c|c|c|c|c|c|c|}
\hline & \multicolumn{3}{|c|}{$\begin{array}{l}\text { Total sample } \\
(n=150)\end{array}$} & \multicolumn{3}{|c|}{$\begin{array}{l}\text { Lower total score (i.e., worsened ability) } \\
\text { at follow-up }(n=65)\end{array}$} & \multicolumn{3}{|c|}{$\begin{array}{l}\text { Higher total score (i.e., improved } \\
\text { ability) at follow-up }(n=36)\end{array}$} \\
\hline & $\begin{array}{l}\text { No item } \\
\text { change }\end{array}$ & $\begin{array}{l}\text { Higher item } \\
\text { score at } \\
\text { follow-up }\end{array}$ & $\begin{array}{l}\text { Lower item } \\
\text { score at } \\
\text { follow-up }\end{array}$ & $\begin{array}{l}\text { No item } \\
\text { change }\end{array}$ & $\begin{array}{l}\text { Higher item } \\
\text { score at } \\
\text { follow-up }\end{array}$ & $\begin{array}{l}\text { Lower item } \\
\text { score at } \\
\text { follow-up }\end{array}$ & $\begin{array}{l}\text { No item } \\
\text { change }\end{array}$ & $\begin{array}{l}\text { Higher item } \\
\text { score at } \\
\text { follow-up }\end{array}$ & $\begin{array}{l}\text { Lower item } \\
\text { score at } \\
\text { follow-up }\end{array}$ \\
\hline Eat soup & $137(91 \%)$ & $7(5 \%)$ & $6(4 \%)$ & $58(89 \%)$ & $3(5 \%)$ & $4(6 \%)$ & $31(86 \%)$ & $3(8 \%)$ & $2(6 \%)$ \\
\hline $\begin{array}{l}\text { Visit family or } \\
\text { friends }\end{array}$ & $129(86 \%)$ & $10(7 \%)$ & $11(7 \%)$ & $56(86 \%)$ & $2(3 \%)$ & $7(11 \%)$ & $26(72 \%)$ & $8(22 \%)$ & $2(6 \%)$ \\
\hline $\begin{array}{l}\text { Care for your } \\
\text { hair and body }\end{array}$ & $129(86 \%)$ & $8(5 \%)$ & $13(9 \%)$ & $53(82 \%)$ & $2(3 \%)$ & $10(15 \%)$ & $29(81 \%)$ & $4(11 \%)$ & $3(8 \%)$ \\
\hline $\begin{array}{l}\text { Dress your } \\
\text { lower body }\end{array}$ & $125(83 \%)$ & $7(5 \%)$ & $18(12 \%)$ & $52(80 \%)$ & $1(2 \%)$ & $12(18 \%)$ & $26(72 \%)$ & $5(14 \%)$ & $5(14 \%)$ \\
\hline $\begin{array}{l}\text { Wash your } \\
\text { upper body }\end{array}$ & $128(85 \%)$ & $10(7 \%)$ & $12(8 \%)$ & $55(85 \%)$ & $3(5 \%)$ & $7(11 \%)$ & $27(75 \%)$ & $4(11 \%)$ & $5(14 \%)$ \\
\hline Take a shower & $124(83 \%)$ & $12(8 \%)$ & $14(9 \%)$ & $53(82 \%)$ & $2(3 \%)$ & $10(15 \%)$ & $27(75 \%)$ & $7(19 \%)$ & $2(6 \%)$ \\
\hline $\begin{array}{l}\text { Wash your } \\
\text { lower body }\end{array}$ & $127(85 \%)$ & $9(6 \%)$ & $14(9 \%)$ & $53(82 \%)$ & $1(2 \%)$ & $11(17 \%)$ & $27(75 \%)$ & $6(17 \%)$ & $3(8 \%)$ \\
\hline Get out of bed & $120(80 \%)$ & $11(7 \%)$ & $19(13 \%)$ & $51(78 \%)$ & $0(0 \%)$ & $14(22 \%)$ & $29(81 \%)$ & $6(17 \%)$ & $1(3 \%)$ \\
\hline Move a chair & $116(77 \%)$ & $14(9 \%)$ & $20(13 \%)$ & $52(80 \%)$ & $1(2 \%)$ & $12(18 \%)$ & $24(67 \%)$ & $9(25 \%)$ & $3(8 \%)$ \\
\hline $\begin{array}{l}\text { Do the dusting/ } \\
\text { cleaning }\end{array}$ & $126(84 \%)$ & $9(6 \%)$ & $15(10 \%)$ & $52(80 \%)$ & $2(3 \%)$ & $11(17 \%)$ & $30(83 \%)$ & $6(17 \%)$ & $0(0 \%)$ \\
\hline $\begin{array}{l}\text { Do the shop- } \\
\text { ping }\end{array}$ & $126(84 \%)$ & $10(7 \%)$ & $14(9 \%)$ & $55(85 \%)$ & $0(0 \%)$ & $10(15 \%)$ & $27(75 \%)$ & $7(19 \%)$ & $2(6 \%)$ \\
\hline $\begin{array}{l}\text { Tie the laces of } \\
\text { your shoes }\end{array}$ & $112(75 \%)$ & $11(7 \%)$ & $27(18 \%)$ & $42(65 \%)$ & $2(3 \%)$ & $21(32 \%)$ & $27(75 \%)$ & $7(19 \%)$ & $2(6 \%)$ \\
\hline $\begin{array}{l}\text { Catch an object } \\
\text { (e.g., a ball) }\end{array}$ & $118(79 \%)$ & $16(11 \%)$ & $16(11 \%)$ & $48(74 \%)$ & $4(6 \%)$ & $13(20 \%)$ & $28(78 \%)$ & $6(17 \%)$ & $2(6 \%)$ \\
\hline $\begin{array}{l}\text { Use dustpan } \\
\text { and brush }\end{array}$ & $111(74 \%)$ & $13(9 \%)$ & $26(17 \%)$ & $45(69 \%)$ & $2(3 \%)$ & $18(28 \%)$ & $22(61 \%)$ & $10(28 \%)$ & $4(11 \%)$ \\
\hline Empty dustbin & $117(78 \%)$ & $12(8 \%)$ & $21(14 \%)$ & $46(71 \%)$ & $1(2 \%)$ & $18(28 \%)$ & $24(67 \%)$ & $10(28 \%)$ & $2(6 \%)$ \\
\hline $\begin{array}{l}\text { Make up your } \\
\text { bed }\end{array}$ & $111(74 \%)$ & $14(9 \%)$ & $25(17 \%)$ & $47(72 \%)$ & $3(5 \%)$ & $15(23 \%)$ & $24(67 \%)$ & $9(25 \%)$ & $3(8 \%)$ \\
\hline Vacuum clean & $119(79 \%)$ & $15(10 \%)$ & $16(11 \%)$ & $50(77 \%)$ & $1(2 \%)$ & $14(22 \%)$ & $27(75 \%)$ & $9(25 \%)$ & $0(0 \%)$ \\
\hline $\begin{array}{l}\text { Serve coffee/ } \\
\text { tea on a tray }\end{array}$ & $111(74 \%)$ & $18(12 \%)$ & $21(14 \%)$ & $51(78 \%)$ & $0(0 \%)$ & $14(22 \%)$ & $20(56 \%)$ & $15(42 \%)$ & $1(3 \%)$ \\
\hline Dance & $107(71 \%)$ & $17(11 \%)$ & $26(17 \%)$ & $40(62 \%)$ & $3(5 \%)$ & $22(34 \%)$ & $26(72 \%)$ & $8(22 \%)$ & $2(6 \%)$ \\
\hline $\begin{array}{l}\text { Stand up from } \\
\text { squatting } \\
\text { position }\end{array}$ & $95(63 \%)$ & $21(14 \%)$ & $34(23 \%)$ & $33(51 \%)$ & $7(11 \%)$ & $25(38 \%)$ & $21(58 \%)$ & $9(25 \%)$ & $6(17 \%)$ \\
\hline $\begin{array}{l}\text { Stand on one } \\
\text { leg }\end{array}$ & $102(68 \%)$ & $18(12 \%)$ & $30(20 \%)$ & $44(68 \%)$ & $1(2 \%)$ & $20(31 \%)$ & $20(56 \%)$ & $13(36 \%)$ & $3(8 \%)$ \\
\hline Walk uphill & $115(77 \%)$ & $8(5 \%)$ & $27(18 \%)$ & $44(68 \%)$ & $1(2 \%)$ & $20(31 \%)$ & $29(81 \%)$ & $6(17 \%)$ & $1(3 \%)$ \\
\hline $\begin{array}{l}\text { Walk three } \\
\text { flights of } \\
\text { stairs }\end{array}$ & $115(77 \%)$ & $15(10 \%)$ & $20(13 \%)$ & $46(71 \%)$ & $5(8 \%)$ & $14(22 \%)$ & $26(72 \%)$ & $8(22 \%)$ & $2(6 \%)$ \\
\hline $\begin{array}{l}\text { Carry and } \\
\text { put down } \\
\text { heavy object } \\
(10 \mathrm{~kg})\end{array}$ & $96(64 \%)$ & $28(19 \%)$ & $26(17 \%)$ & $39(60 \%)$ & $5(8 \%)$ & $21(32 \%)$ & $17(47 \%)$ & $16(44 \%)$ & $3(8 \%)$ \\
\hline Run & $116(77 \%)$ & $16(11 \%)$ & $18(12 \%)$ & $46(71 \%)$ & $4(6 \%)$ & $15(23 \%)$ & $24(67 \%)$ & $11(31 \%)$ & $1(3 \%)$ \\
\hline
\end{tabular}

Data reported as $n(\%)$. Because of rounding, percentages might not add up to $100 \%$ exactly. In total, $n=49$ patients had the same DM1-Activ ${ }^{\mathrm{C}}$ total score at baseline and the follow-up visit. A higher/lower score indicates a higher/lower ability to perform activities of daily living 
was "Carry and put down heavy object (10 kg)", where $19 \%$ (28 of 150) had a higher item score at follow-up, followed by "Stand up from squatting position" (14\%, 21 of 150), and "Serve coffee/tea on a tray" and "Stand on one leg" (12\%, 18 of 150 , respectively). The item with the largest negative change was "Stand up from squatting position", where 23\% (34 of 150) had a lower item score at follow-up, followed by "Stand on one leg" $(20 \%, 30$ of 150), and "Tie the laces of your shoes" and "Walk uphill" (18\%, 27 of 150, respectively).

We found the annual change in the DM1-Activ ${ }^{\mathrm{C}}$ total score to be related to the total score at baseline (i.e., patients' baseline ability to perform activities of daily living) $(p=-0.20, p=0.015)$, but not estimated progenitor or modal allele CTG repeat length $(p=0.937$ and $p=0.897$, respectively), disease duration $(p=0.712)$, or baseline MIRS or 6MWT result ( $p=0.901$ and $p=0.567$, respectively). Results from our regression analysis revealed that each ten-point change in the DM1-Activ ${ }^{\mathrm{C}}$ total score at baseline was associated with a mean annual total score change of -1.37 (SE: $0.66,95 \% \mathrm{CI}-2.68$ to $-0.06, p=0.041$ ) when adjusting for age, sex, and estimated progenitor CTG repeat length (full model results available as supplemental material online).

\section{Discussion}

The objective of this study was to investigate change over time in ability to perform activities of daily living as measured using the DM1-Activ ${ }^{\mathrm{C}}$ in patients with DM1. Taken together, our results reveal substantial heterogeneity in changes across follow-up in DM1-Activ ${ }^{\mathrm{C}}$ total scores at the population level. Indeed, almost half of our sample (43\%) had a lower score at the follow-up visit (indicating a decreased ability to perform activities of daily living), $24 \%$ a higher score (indicating an increased ability), and 33\% the same score at baseline and follow-up. Results from the 6MWT were distributed in line with these findings, showing a markedly greater decline for those with a lower DM1Activ $^{\mathrm{C}}$ total score at the follow-up. In addition, we found baseline ability to perform activities of daily living to be significantly associated with annual change in total scores, but not sex, disease duration, timed test results, or CTG repeat length. These data should be helpful to inform the design of future studies based on the DM1-Activ ${ }^{\mathrm{C}}$.

Comparing our results with previous research, changes in DM1-Activ ${ }^{\mathrm{C}}$ total scores have been estimated and reported as part of the OPTIMISTIC trial in patients with DM1 with severe fatigue [8]. In that study, the unadjusted mean change in the total score across follow-up (comprising 10 months) for patients receiving cognitive behavioral therapy with optional graded exercise therapy $(n=128$; mean age:
45 years; $45 \%$ female) was estimated at 2.70 . For patients receiving standard of care ( $n=127$; mean age: 46 years; $47 \%$ female), the mean change was -2.21 . Adjusting our estimates to reflect the same follow-up duration, the unadjusted mean change in the DM1-Activ ${ }^{\mathrm{C}}$ total score in our sample was $-1.72(95 \% \mathrm{CI}-2.95$ to -0.49$)$. However, it should be emphasized that these studies are not directly comparable due to non-trivial differences concerning demographic and clinical characteristics of the sample populations.

We found that replies to only a limited set of items changed from baseline to end of follow-up (Table 2). Specifically, in the total sample, replies to only three individual items changed during follow-up for $>30 \%$ of patients, and 15 items for $>20 \%$. Moreover, changes to replies to all but two items, namely "Eat soup" and "Carry and put down heavy object $(10 \mathrm{~kg})$ ", were indicative of lost ability (i.e., a net negative change in item scores). Notable examples of items for which a larger proportion of patients with any change had a lower as opposed to higher score at follow-up include "Walk uphill" (18\% vs. 5\%), "Tie the laces of your shoes" (18\% vs. $7 \%)$ and "Stand up from squatting position" (23\% vs. $14 \%)$. Looking at the subset of patients with a higher total score at follow-up, items with the largest positive change were "Carry and put down heavy object (10 kg)", "Serve coffee/tea on a tray", and "Stand on one leg". To our surprise, $44 \%$ of these patients indicated an improvement in their ability to "Carry and put down heavy object $(10 \mathrm{~kg})$ " across follow-up. Furthermore, for this subgroup, the only items where $>10 \%$ of patients had a lower score at follow-up were "Stand up from squatting position", "Use dustpan and brush", "Dress your lower body", and "Wash your upper body". The items with the largest negative change in the group of patients with a lower total score at follow-up were "Stand up from squatting position" and "Dance". Indeed, for these two items, more than one-third of patients had a lower item score at the end of follow-up. Only one item ("Stand up from squatting position") had a positive change in $>10 \%$ of patients in this subgroup. Taken together, these data show that change over time in ability to perform activities of daily living as recorded using the DM1-Activ ${ }^{\mathrm{C}}$ is highly variable in DM1, and that changes (negative, as well as positive) seem to involve gross and fine motor skills of both the upper and lower extremities. In terms of measuring annual change, our analysis also reveals that some items appear to be lacking relevance at the population level with respect to the underlying, highly variable natural evolution of the disease. More research is needed to fully understand these properties of the DM1-Activ ${ }^{\mathrm{C}}$.

The minimal clinically important difference in DM1Activ $^{\mathrm{C}}$ total scores is yet to be estimated. For this reason, it is not straightforward to interpret the magnitude of the annual changes reported as part of this work. Still, considering that a one-point change at the item level means that a 
specific task no longer can be performed without difficulty, or at all, and given the fact that items within the DM1-Activ ${ }^{\mathrm{C}}$ captures common activities of daily living involving significant muscle function, it could be argued that even a onepoint change would be meaningful from the perspective of the individual patient.

As mentioned in brief above, results from our adjusted regression analysis showed that the baseline DM1-Activ ${ }^{\mathrm{C}}$ total score was significantly associated with the annual change in total score. Specifically, we found that patients with a higher score at baseline had a larger negative change across follow-up when controlling for age, sex, and estimated progenitor CTG repeat length. Although a diminishing marginal loss in ability in relation to the initial level of ability may appear intuitive (i.e., the more ability you possess, the more you can theoretically lose over time), this result would be expected to be of importance when designing trials involving the DM1-Activ ${ }^{\mathrm{C}}$. In particular, our data suggests that it may be challenging to conduct meaningful measurement of changes in ability to perform activities of daily living over time using the DM1-Activ ${ }^{\mathrm{C}}$ in patient populations characterized by a low starting level of ability. That being said, it is important to keep in mind that additional research is needed to confirm our findings, preferably in a larger sample with an even greater diversity of ability at baseline.

The main limitation of our study concerns the precision and external validity of our results due to the relatively small number of patients in comparison with research of more common illnesses. Yet, it should be noted that our sample of 150 patients is large in the context of studies in DM1 [15]. In addition, the DM1-Activ ${ }^{\mathrm{C}}$ data may be subject to bias due to, for example, incorrect reporting. This issue would be expect to be of particular relevance in populations characterized by some degree of cognitive impairment, such as DM1. However, per the study procedures, patients with significant cognitive impairment were not eligible to participate, which should help minimize errors associated with the data collection. Another potential source of variability across follow-up includes learning effects, where patients' experience of the DM1-Activ ${ }^{\mathrm{C}}$ at baseline may influence their assessment at follow-up $[4,16]$. We were also unable to unable to infer causality behind identified associations due to the observational nature of our data. Finally, when interpreting our regression analysis results, it is important to keep in mind that the estimated coefficients may be subject to unmeasured confounding.

In conclusion, we show that change over time in ability to perform activities of daily living as recorded through the DM1-Activ ${ }^{\mathrm{C}}$ varies substantially between patients with DM1. Our data contribute to the understanding of the natural evolution of the disease, and should be helpful to inform the design of future trials based on the DM1-Activ ${ }^{\mathrm{C}}$.
Acknowledgements Open access funding provided by Karolinska Institute. The authors would like to thank all the participants and collaborators involved in PhenoDM1.

Funding This study has been supported by the National Institute of Health Research (NIHR) under the RD-TRC programme and by the Wyck Foundation.

Data availability The data that support the findings of this study are not publicly available due to privacy or ethical restrictions.

\section{Compliance with ethical standards}

Conflicts of interest Dr. Landfeldt is an employee of ICON plc (Stockholm, Sweden), outside the submitted work. Dr. Monckton reports having a research contract with Newcastle University during the conduct of the study; personal fees from AMO Pharma, Vertex, Charles River, BridgeBio, Small molecule RNA, and personal fees for scientific advisory board membership from Triplet Therapeutics and LoQus23, outside the submitted work. Dr. Monckton is on the scientific advisory board of the Myotonic Dystrophy Foundation and is a scientific advisor to the Myotonic Dystrophy Support Group. Dr. Faber reports research support from the European Union's Horizon 2020 research and innovation programme Marie Sklodowska-Curie grant for PAIN-Net, Molecule-to-man pain network (grant no. 721841), the European Union 7th Framework Programme (Grant no. 602273) for the PROPANE study, Prinses Beatrix Spierfonds, and Grifols and Lamepro for a trial on IVIg in small fibre neuropathy, outside the submitted work. Dr. Faber has participated in steering committees for studies in small fibre neuropathy of Biogen/Convergence and Vertex outside the submitted work. Dr. Merkies received funding for research from the Talecris Talents program, the GSB CIDP Foundation International, Princes Beatrix foundation, and from the European Union 7th Framework Programme (Grant no. 602273) outside the submitted work. Furthermore, a research foundation at the University of Maastricht received honoraria on behalf of Dr. Merkies for participation in steering committees of the Talecris ICE Study, LFB, CSL Behring, Novartis, Grifols, and Octapharma outside the submitted work. Dr. Merkies serves on the editorial board of the Journal of Peripheral Nervous system, is a member of the Inflammatory Neuropathy Consortium (INC), and member of the Peripheral Nerve Society. Dr. Turner reports financial support from the Biomedical Research Council and the National Brain Appeal. Dr. Lochmüller is an investigator of the Medical Research Council UK Centre for Neuromuscular Diseases (reference G1002274, grant ID 98482). The other authors report no conflicts of interest.

Open Access This article is licensed under a Creative Commons Attribution 4.0 International License, which permits use, sharing, adaptation, distribution and reproduction in any medium or format, as long as you give appropriate credit to the original author(s) and the source, provide a link to the Creative Commons licence, and indicate if changes were made. The images or other third party material in this article are included in the article's Creative Commons licence, unless indicated otherwise in a credit line to the material. If material is not included in the article's Creative Commons licence and your intended use is not permitted by statutory regulation or exceeds the permitted use, you will need to obtain permission directly from the copyright holder. To view a copy of this licence, visit http://creativecommons.org/licenses/by/4.0/. 


\section{References}

1. Harper PS (2001) Myotonic dystrophy, 3rd edn. W.B. Saunders, London

2. Laberge L, Mathieu J, Auclair J et al (2013) Clinical, psychosocial, and central correlates of quality of life in myotonic dystrophy type 1 patients. Eur Neurol 70(5-6):308-315

3. Bouchard JP, Cossette L, Bassez G, Puymirat J (2015) Natural history of skeletal muscle involvement in myotonic dystrophy type 1: a retrospective study in 204 cases. J Neurol 262(2):285-293

4. Gagnon C, Heatwole C, Hébert LJ et al (2018) Report of the third outcome measures in myotonic dystrophy type 1 (OMMYD-3) international workshop Paris, France, June 8, 2015. J Neuromuscul Dis. https://doi.org/10.3233/JND-18032 9(Epub ahead of print)

5. Hobart JC, Cano SJ, Zajicek JP et al (2007) Rating scales as outcome measures for clinical trials in neurology: problems, solutions, and recommendations. Lancet Neurol 6:1094-1105

6. Hermans MC, Faber CG, De Baets MH, de Die-Smulders CE, Merkies IS (2010) Rasch-built myotonic dystrophy type 1 activity and participation scale (DM1-Activ). Neuromuscul Disord 20(5):310-318

7. Hermans MC, Hoeijmakers JG, Faber CG, Merkies IS (2015) Reconstructing the rasch-built myotonic dystrophy type 1 activity and participation scale. PLoS ONE 10(10):e0139944. https:// doi.org/10.1371/journal.pone.0139944

8. Okkersen K, Jimenez-Moreno C, Wenninger S, Daidj F, Glennon J, Cumming S et al (2018) Cognitive behavioural therapy with optional graded exercise therapy in patients with severe fatigue with myotonic dystrophy type 1: a multicentre, single-blind, randomised trial. Lancet Neurol 17(8):671-680

9. Rasch G (1960) Probabilistic models for some intelligence and attainment tests (1st Edition). Danish Institute for Education Research, Copenhagen

10. Wright B (1997) A history of social science and measurement. Educ Meas 52:33-52

11. Hobart J, Cano S (2009) Improving the evaluation of therapeutic interventions in multiple sclerosis: the role of new psychometric methods. Health Technol Assess 13(12):1-177

12. Morales F, Couto JM, Higham CF et al (2012) Somatic instability of the expanded CTG triplet repeat in myotonic dystrophy type 1 is a heritable quantitative trait and modifier of disease severity. Hum Mol Genet 21:3558-3567

13. Gomes-Pereira M, Bidichandani SI, Monckton DG (2004) Analysis of unstable triplet repeats using small-pool polymerase chain reaction. Method Mol Biol 277:61-76

14. Monckton DG, Wong L-JC, Ashizawa T, Caskey CT (1995) Somatic mosaicism, germline expansions, germline reversions and intergenerational reductions in myotonic dystrophy males: small pool PCR analyses. Hum Mol Genet 4(1):1-8

15. Landfeldt E, Edström J, Jimenez-Moreno C et al (2019) Healthrelated quality of life of patients with adult onset myotonic dystrophy type 1: a systematic review. Patient. https://doi.org/10.1007/ s40271-019-00357-y

16. Symonds T, Randall JA, Campbell P (2017) Review of patientreported outcome measures for use in myotonic dystrophy type 1 patients. Muscle Nerve 56(1):86-92

\section{Affiliations}

\section{Erik Landfeldt ${ }^{1}$ (D) Nikoletta Nikolenko ${ }^{2} \cdot$ Cecilia Jimenez-Moreno $^{3,4} \cdot$ Sarah Cumming $^{5} \cdot$ Darren G. Monckton $^{5}$. Catharina G. Faber ${ }^{6}$ Ingemar S. J. Merkies ${ }^{6,7} \cdot$ Grainne Gorman $^{8} \cdot$ Chris Turner $^{2,9} \cdot$ Hanns Lochmüller ${ }^{10,11}$}

1 Department of Women's and Children's Health, Karolinska Institutet, Karolinska Vägen 37A, 17176 Stockholm, Sweden

2 National Hospital for Neurology and Neurosurgery, Queen Square, University College London Hospitals NHS Foundation Trust, London, UK

3 Welcome Center for Mitochondrial Research, Translational and Clinical Research Institute, Newcastle University, Newcastle upon Tyne, UK

4 Patient-Centered Research, Evidera, London, UK

5 Institute of Molecular, Cell and Systems Biology, College of Medical, Veterinary and Life Sciences, University of Glasgow, Glasgow, UK

6 Department of Neurology, School of Mental Health and Neuroscience, Maastricht University Medical Center, Maastricht, The Netherlands
7 Department of Neurology, Curaçao Medical Centre, Willemstad, Curaçao

8 Institute of Neuroscience, Wellcome Trust Centre for Mitochondrial Research, University of Newcastle, Newcastle, UK

9 Queen Square Department of Neuromuscular Disease, University College London, London, UK

10 Department of Neuropediatrics and Muscle Disorders, Medical Centre, Faculty of Medicine, University of Freiburg, Freiburg, Germany

11 Children's Hospital of Eastern Ontario Research Institute; Division of Neurology, Department of Medicine, The Ottawa Hospital; and Brain and Mind Research Institute, University of Ottawa, Ottawa, Canada 